\title{
Surgical treatment of hydatid cysts of the lung: report on 1055 patients
}

\author{
RIZA DOGAN, MUSTAFA YÜKSEL, GÜVEN ÇETIN, KAYA SÜZER, METE ALP, \\ SADI KAYA, MEHMET ÜNLÜ, BÜLENT MOLDIBI \\ From the Department of Thoracic Surgery, Atatürk Chest Disease and Surgical Centre, Ankara, Turkey
}

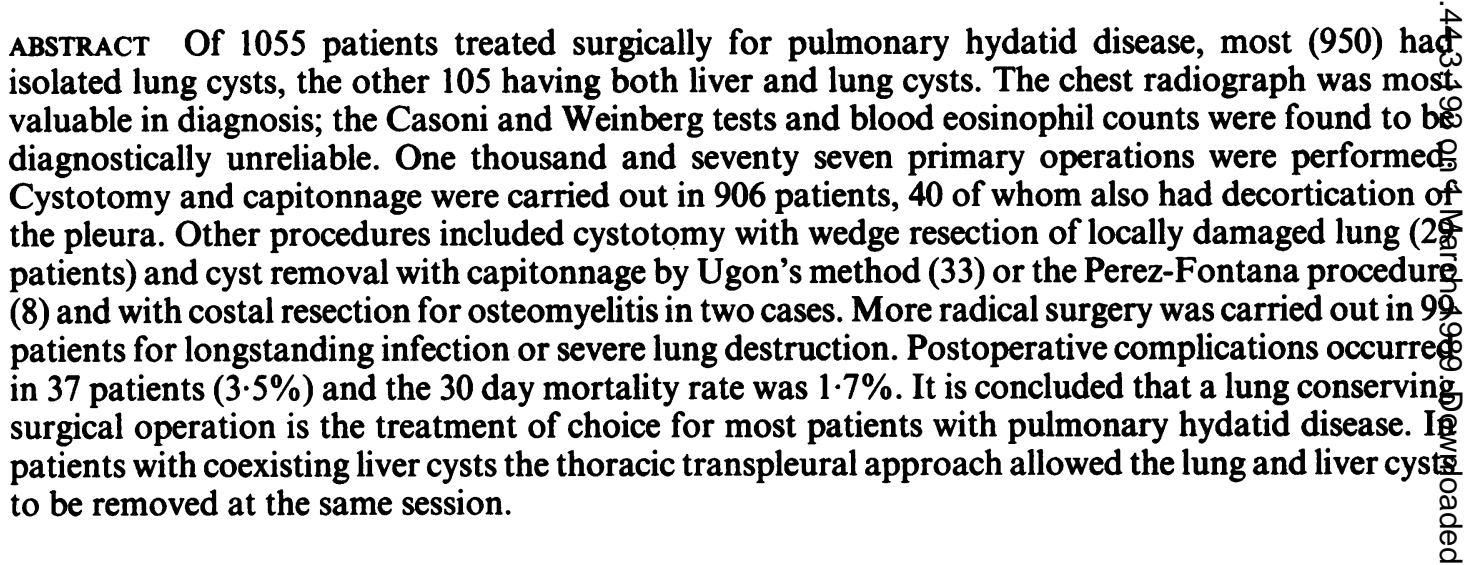

\section{Introduction}

Hydatid disease, caused by Echinococcus granulosus, is endemic in some countries, particularly those in which sheep and cattle are raised, such as Australia, New Zealand, the Mediterranean countries, the Middle East, and South America. ${ }^{1-7}$ In Turkey, where the incidence of hydatid disease is said to be $20 / 1000000$, it is particularly common in the rural population. In this population the lung is the most common site for hydatid cysts after the liver. ${ }^{7-9}$ In our own hospital, one of five major thoracic surgery clinics in Turkey, surgery for hydatid disease accounted for $25 \%$ of the 4419 surgical operations performed from 1971 to 1987.

In this article we report our experience of the surgical management of 1055 cases of pulmonary hydatidosis.

\section{Patients and methods}

PATIENTS

During 1971-87 1115 patients with pulmonary

Address for reprint requests: Dr Riza Doğan, Atatürk Göguüs Hastalıkları ve Göğüs Cerrahisi, Merkezi, Keçiören, Ankara, Turkey.

Accepted 2 December 1988 hydatidosis were treated surgically in our hospita $\overrightarrow{\vec{b}}$ Sixty patients had bilateral disease that was treate surgically from 1979 to 1987 through a median sternotomy and these are excluded from this report. Our report concerns the remaining 1055 patients $\left(546^{*}\right.$ male, 509 female), who were aged 3-85 (mean 27.5 years. Most patients $(87 \%)$ were from rural areas an $13 \%$ from urban areas. Of these patients, $950(90 \%$ had isolated pulmonary cysts and 105 coexisting hepatic hydatidosis (12 with intrathoracic extension of the liver cysts).

\section{SURGICAL TECHNIQUE}

All patients were treated surgically, a posterolatersf thoracotomy approach being used. The 22 patients with bilateral disease were managed with stage thoracotomies, so that in all 1077 operations were performed on the 1055 patients (table 1).

Cystotomy and capitonnage, our preferred tecle nique, was carried out in 906 patients (84\%). The cy震 was usually seen as a soft swelling on the surface of the pulmonary parenchyma. The thoracotomy wound and the lung, apart from the area containing the cyst were covered with sponges moistened with salin to prevent inadvertent implantation of scolices of daughter cysts. The lung was kept inflated, and a large 
Table 1 Operative methods used in 1055 patients*

\begin{tabular}{|c|c|c|c|}
\hline \multicolumn{2}{|l|}{$\begin{array}{l}\text { Type of } \\
\text { operation }\end{array}$} & $\begin{array}{l}\text { No of } \\
\text { cases }\end{array}$ & $\begin{array}{l}\text { Rate } \\
(\%)\end{array}$ \\
\hline \multicolumn{4}{|c|}{ CONSERVATIVE } \\
\hline \multicolumn{2}{|c|}{ Cystotomy and capitonnage } & 906 & $84 \cdot 1$ \\
\hline \multicolumn{2}{|c|}{$\begin{array}{l}\text { Cystotomy and wedge resection of } \\
\text { the parenchyma }\end{array}$} & 29 & $2 \cdot 7$ \\
\hline \multicolumn{2}{|c|}{ Enucleation and capitonnage (Ugon or } & 33 & $3 \cdot 1$ \\
\hline \multicolumn{2}{|c|}{ Cystectomy (Perez-Fontana method) } & 8 & 0.7 \\
\hline \multicolumn{2}{|c|}{$\begin{array}{l}\text { Cystectomy and costal resection } \\
\text { with myoplasty }\end{array}$} & 2 & 0.2 \\
\hline \multicolumn{2}{|l|}{ Segmentectomy } & $\begin{array}{l}27 \\
71\end{array}$ & $\begin{array}{l}2.5 \\
6.6\end{array}$ \\
\hline $\begin{array}{l}\text { Left upper } \\
\text { Left lower } \\
\text { Right upper } \\
\text { Right middle } \\
\text { Right lower } \\
\text { Right inferior bilobectomy }\end{array}$ & $\begin{array}{r}13 \\
11 \\
11 \\
21 \\
13 \\
2\end{array}$ & & \\
\hline Pneumonectomy & & 1 & $0 \cdot 1$ \\
\hline
\end{tabular}

*Two stage thoracotomy was performed in 22 patients who had bilateral pulmonary hydatidosis.

needle connected to the suction tip was inserted into the cyst. When the cystic material had been aspirated as completely as possible, the most prominent part of the cyst was opened with cautery (cystotomy). The tip of a large suction tube was introduced immediately through the same opening to evacuate the remaining cystic material. The germinative membrane was then removed with ring forceps, the residual cavity irrigated with saline, and the bronchial openings sutured. The residual cavity was obliterated by means of pursestring sutures starting from the deepest level, a space of 1.5-2 $\mathrm{cm}$ being left between each layer of sutures (capitonnage). Non-absorbable suture material was used initially, but since 1974 the bronchi and residual cavity have been closed with coated polygalactin 910 (Coated Vicryl, Ethicon, Somerville, New Jersey) sutures. Forty patients had the thickened pleura decorticated, in addition to cystotomy and capitonnage, to facilitate expansion of the lung.

Other procedures were carried out in certain patients. In 29 patients undergoing cystotomy the pericystic lung parenchyma was resected, as it was partially atelectatic and not expected to expand after surgery. In 33 patients the cyst was removed intact according to the Ugon or Barrett method (enucleation and capitonnage). ${ }^{1011}$

In eight patients the Perez-Fontana procedure ${ }^{12}$ was performed, the cyst being removed with the pericyst and the residual cavity obliterated. Two patients with infected cysts on the surface of the lung had osteomyelitis in the adjacent ribs, so a limited costal resection and myoplasty (not the Perez-Fontana procedure) was performed in addition to cystectomy.

More radical procedures, such as segmentectomy, lobectomy, and pneumonectomy, were performed in 99 patients because chronic inflammation and bronchiectatic changes were present in the surrounding lung tissue. In 10 of these patients liver cysts extended into the thorax (right middle lobectomy in seven cases, right lower lobectomy in three).

Coexisting liver cysts (105) were managed transdiaphragmatically after the lung cysts had been dealt with. Most were in the right lobe of the liver $(72,69 \%)$. Daughter cysts were found in $42(40 \%)$ cases. The surgical technique varied according to the features and size of the cyst. In 79 patients cystotomy and indwelling tube drainage were performed, a subdiaphragmatically placed tube drain being retained until there was complete closure of the residual cavity. In the remaining 26 patients cystotomy and capitonnage were performed in the classical way as described above. The diaphragmatic opening was closed in two layers and an underwater seal drainage tube left in the pleural cavity.

\section{Results}

\section{PRESENTATION}

Although cough, purulent sputum, fever, and chest pain were common presenting symptoms (table 2), 342 $(32 \%)$ patients were symptom free, their cysts being diagnosed from a routine chest radiograph. Oval or spherical opacities in the lung fields on routine chest radiographs were considered to be diagnostic of uncomplicated cysts (fig 1). The 525 patients with perforated cysts had various radiographic signs, including the water lily sign (fig 2), the meniscus sign (fig 3), incarcerated membranes (fig 4), air-fluid levels, hydropneumothorax (fig 5), pneumothorax (fig 6), and a simple cavity. In the series as a whole a preoperative diagnosis of hydatid disease based upon the chest radiograph was correct in $99 \%$ of patients. The postoperative diagnoses in the other patients were bronchogenic cyst (3), hamartoma (1), pulmonary arteriovenous fistula (1), benign granuloma (1), and metastatic adenocarcinoma (1).

When hydatid disease was suspected from the initial chest radiograph other tests were carried out as indicated, including the Casoni skin test, the Weinberg reaction, the peripheral blood eosinophil count, the

Table 2 Clinical manifestations in 1055 patients

\begin{tabular}{ll}
\hline Clinical manifestation & No of cases \\
\hline Cough & 320 \\
Purulent sputum & 212 \\
Fever & 116 \\
Chest pain & 114 \\
Haemoptysis & 41 \\
Allergic reaction & 3 \\
Asymptomatic & 342 \\
\hline
\end{tabular}




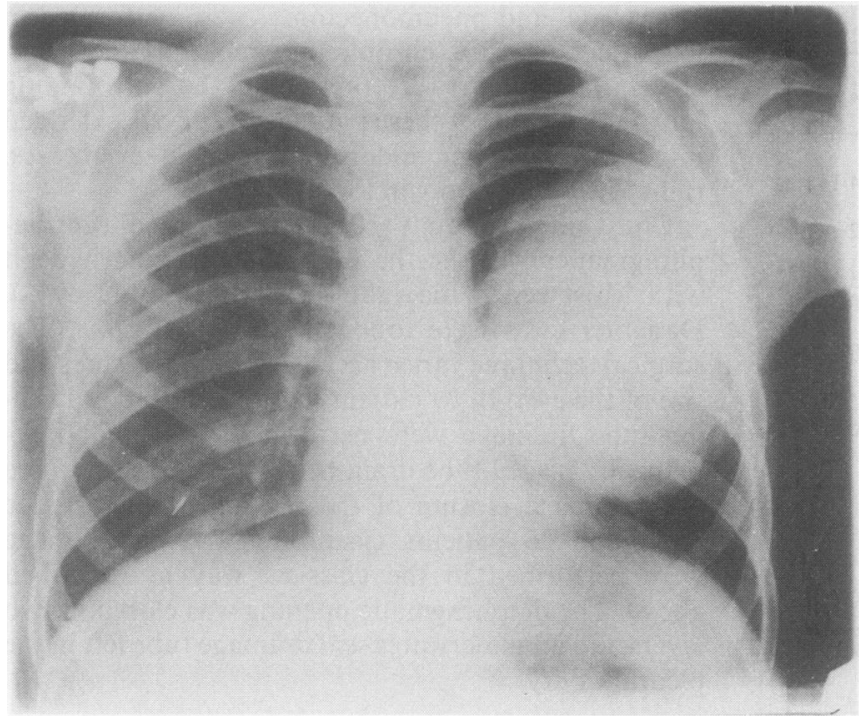

Fig 1 Uncomplicated cyst in an 8 year old child.

erythrocyte sedimentation rate, and abdominal ultrasonography. The Casoni skin test or the Weinberg reaction test or both were carried out in 157 of 393 patients and results were positive in $52 \%$ of patients. They were discontinued in 1978 because of their low diagnostic yield and the false negative results. The eosinophil count was also discontinued in 1978 as only 38 of 112 patients had a high count. Since 1978 abdominal ultrasonography has been performed routinely to determine whether liver cysts were present.

The cysts were located in the right lung in 632 patients $(60 \%)$, in the left lung in 401 patients $(38 \%)$, and in both lungs in 22 patients $(2 \%)$. The lower lobes were affected more often than the upper lobes (528 versus $\mathbf{3 6 1}$ for single cysts) (fig 7). Multiple pulmonary cysts were found in 75 patients, being bilateral in 22 (fig 8).

The lung cysts were intact and uncomplicated in 469 patients and had ruptured in 525 patients $(502$ of these were infected). Sixty one of the 75 patients with multiple pulmonary cysts had both intact and ruptured cysts.

\section{OUTCOME OF SURGERY}

Two patients $(0 \cdot 2 \%)$ died during surgery, both deaths occurring during the induction of anaesthesia. A further 16 patients died from various causes in the 30 days after surgery (table 3 ). The remaining patients were followed for eight months. Although continuing follow up was attempted through the hospital in the area where the patient lived, details are available for only 350 patients.

The most common complication in the early post- operative period was empyema (table 4). Thiš occurred in 13 patients, all of whom had had a hydatid cyst that was infected and perforated at the time ofo surgery. Ten of the patients were treated successfully by tube drainage and a 15 day course of antibiotics. The remaining three patients (two with a coexisting? liver cyst) died of septic shock.

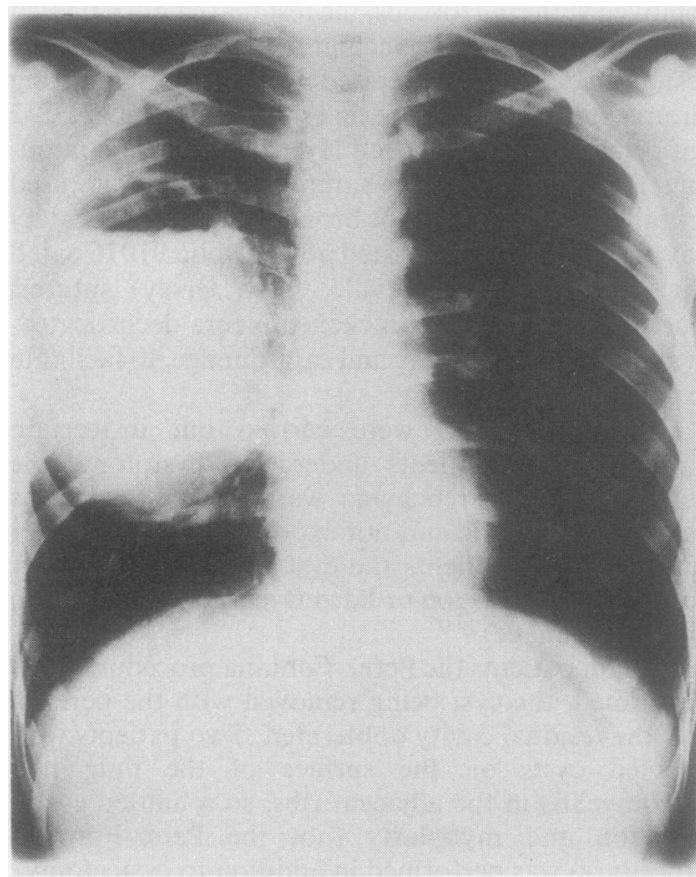

Fig 2 Typical water lily sign. 


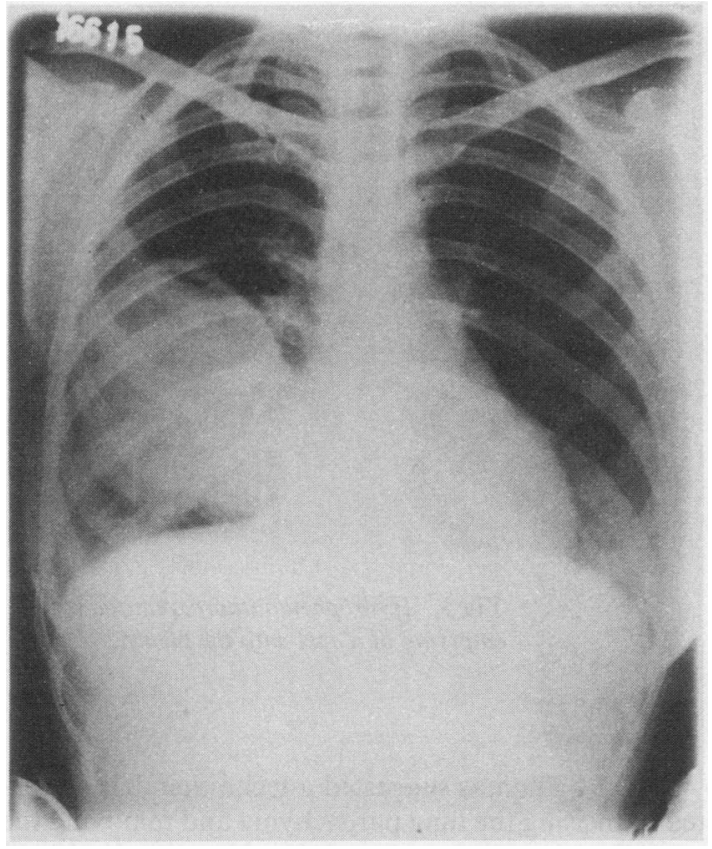

Fig 3 Meniscus sign of a cyst in the right lower lobe.

Bronchobiliary fistula developed in five patients with a coexisting liver cyst that had been treated by cystotomy and drainage without capitonnage. The fistula was treated successfully by tube drainage followed by open drainage in three patients, and in the remaining two nasoduodenobiliary drainage was performed on the 25th and 34th postoperative days. Haemorrhage occurred in three patients.

There were several late postoperative complications. The hydatid cysts recurred in eight patients, within the same lobe and in the year after operation in six. In seven of the eight patients the cysts had been ruptured at the time of initial surgery. Two patients underwent lobectomy as they had multiple cysts in the right middle and lower lobes; four underwent cystotomy and capitonnage; and the remaining two, who had multiple cystic recurrences along the thoracotomy incision, were treated with mebendazole $(50 \mathrm{mg} / \mathrm{kg} \mathrm{a}$ day in three divided doses) for six months. This caused a dramatic recovery in one patient but was unsatisfactory in the other, who required surgical excision. Two patients with recurrent haemoptysis had a segmentectomy and one patient, who had developed bronchiectatic changes three years after surgery, had a right middle lobectomy. Three patients developed empyema in the late postoperative period, which was due to recurrence of the cavities with infection in the previously capitonnated cystic space. Complete recovery was achieved with drainage and antibiotic treatment.

All the complications occurred in the group treated by conservative surgery, though all had also had ruptured or infected cysts (or both) before operation. The complication rate in this group was $3.8 \%$. The group treated with radical surgery had no cyst related complication except for a persistent air leak in three patients $\left(\chi^{2}=3.88, p<0.05\right)$. The incidence of complications was lower in patients with isolated lung cysts $(2.9 \%)$ than in those with coexisting liver cysts $(8.6 \%)$ (table 4).

\section{Discussion}

Hydatid disease has been known since the time of Hippocrates. ${ }^{13}$ Since then the epidemiology and clinical features of the disease have been well described. ${ }^{14}$ Rarely, lung cysts heal by spontaneous rupture and evacuation into the bronchus, ${ }^{5-7}$ though complications such as infection, abcess formation, bronchogenic spread, and anaphylactic shock may occur.

The results of treatment of hydatid disease with mebendazole and albendazole during the last 10 years have been described. ${ }^{15-19}$ From 1978 to 198228 patients were treated with oral mebendazole, $35-50 \mathrm{mg} / \mathrm{kg}$ daily in three divided doses for four to six months, in

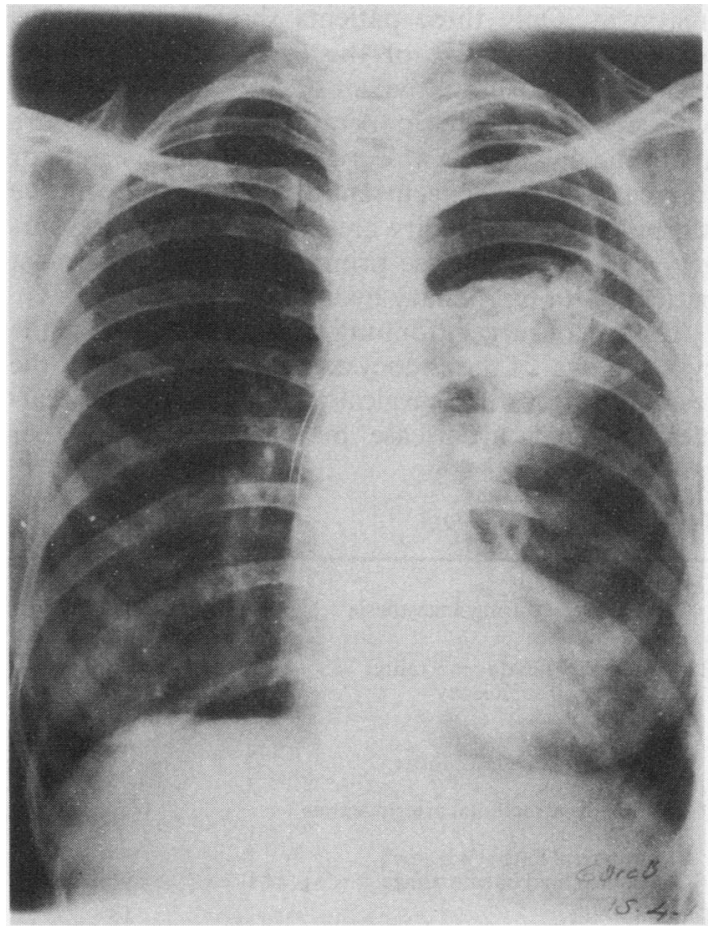

Fig 4 Incarcerated membranes in a left upper lobe cyst. 
Doğan, Yüksel, Çetin, Süzer, Alp, Kaya, Ünlü, Moldibi

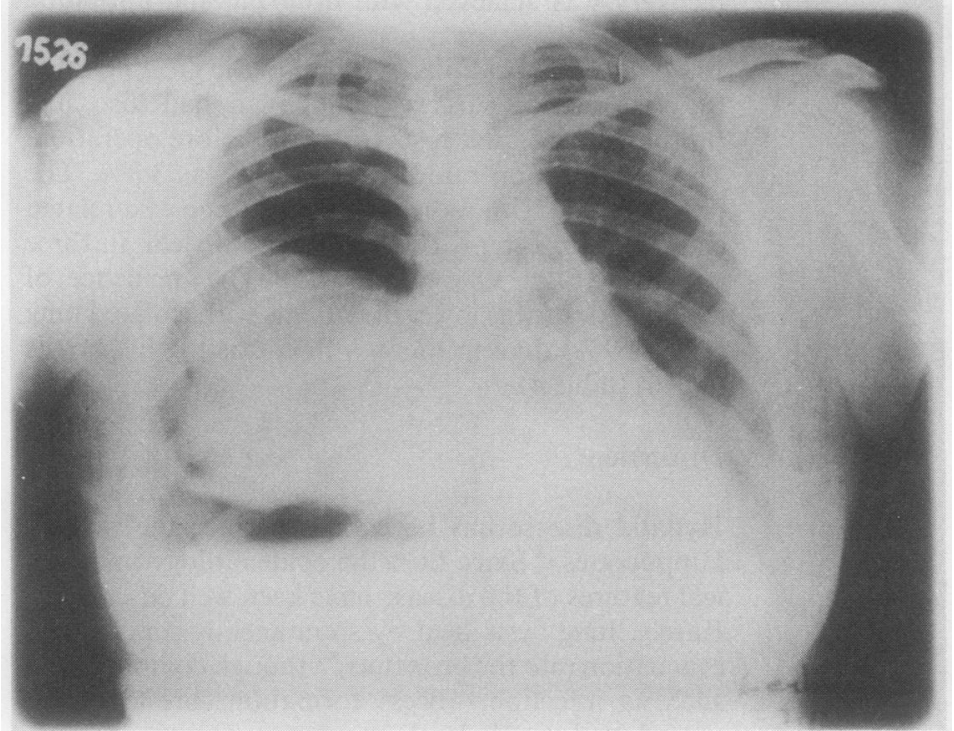

Fig 5 Hydropneumothorax caused by emptying of a cyst into the pleura.

our clinic. The blood concentration of the drug could not be monitored and follow up was possible for only 22 patients. Overall treatment was disappointing. Four patients required urgent surgery for massive haemoptysis after four to six weeks' treatment, and in six patients the cyst ruptured into the bronchus during treatment. Only three patients showed an obvious reduction in the size of the cysts. In our opinion chemotherapy should be considered only in patients with cysts that are inoperable (because they are anatomically inaccessible or the patient is a poor surgical risk) or for recurrent disease, when operative morbidity and mortality are higher. At present, surgery should remain the primary treatment for most patients with pulmonary hydatid disease.

The aim of surgery for lung cysts is evacuation of the cyst, removal of the endocyst, and management of the residual cavity. The surgical procedure for the treatment of hydatid disease may be conservative or radical. $^{515}$

Table 3 Causes of death

\begin{tabular}{lll}
\hline $\begin{array}{l}\text { Operative mortality } \\
\text { Cardiac arrest during anaesthesia }\end{array}$ & 2 \\
$\quad$ induction & 2 & \\
$\begin{array}{l}\text { Early mortality (30 day mortality) } \\
\text { Respiratory insufficiency }\end{array}$ & 16 \\
Septic shock & 4 & \\
Fibrinolysis & 3 & \\
Contralateral pneumothorax & 2 & \\
Toxic hepatitis & 2 & \\
Rupture of intracranial arteriovenous & 2 & \\
$\quad$ fistula & 1 & \\
Contralateral lung syndrome* & 1 & \\
Gastrointestinal haemorrhage & 1 & \\
Total mortality & \\
\hline
\end{tabular}

*Down lung syndrome.
In 1884 Thomas suggested a technique that consis ted of incising the lung parenchyma and removing the cyst. ${ }^{5}$ Enucleation was reported by Ugon et al in $1946^{16}$ and Barrett in 1947," who described removal of thes

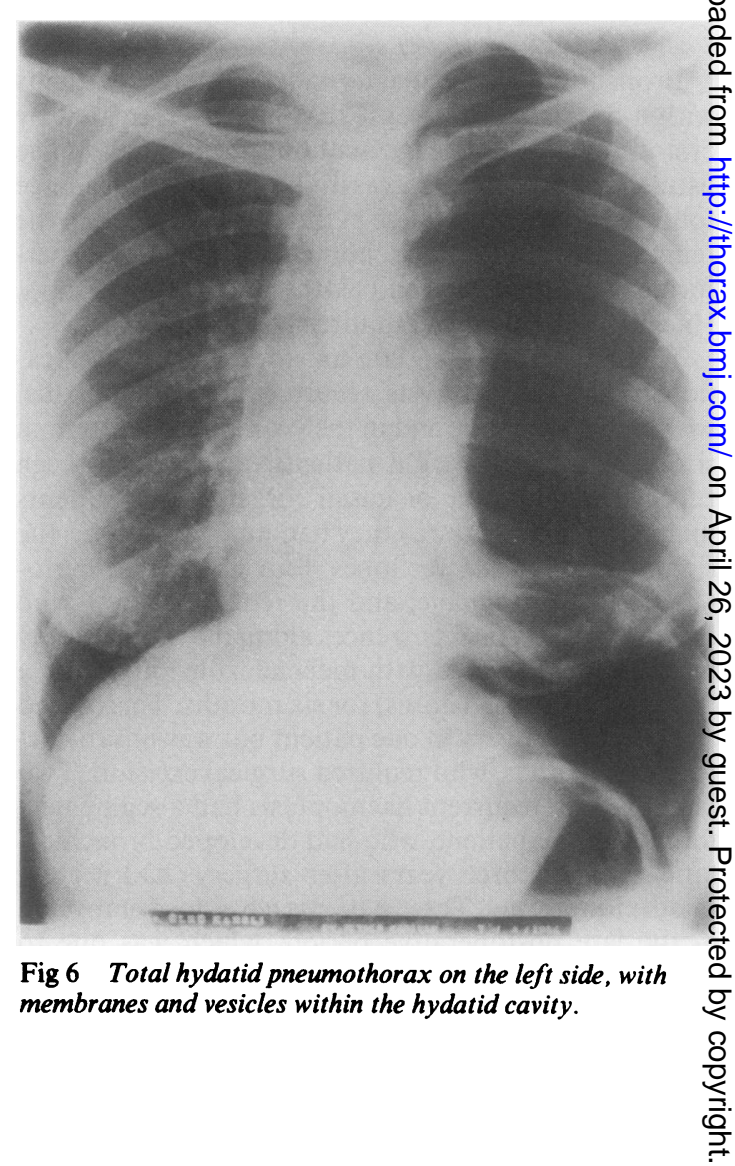



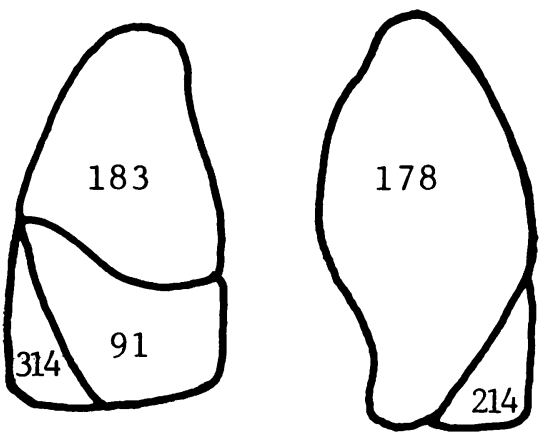

SINGLE CYSTS $(n=980)$
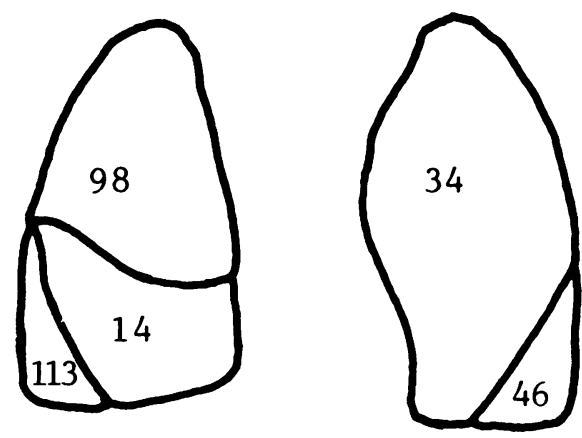

MULTIPLE CYSTS $(n=305)$

Fig 7 Distribution of hydatid cysts in relation to lungs and lobes (numbers refer to cysts, not patients).

parasite and obliteration of the remaining cavity with a series of pursestring sutures (capitonnage). In the same year Allende described simple enucleation of the cyst without capitonnage of the residual cavity. ${ }^{20}$ Perez-Fontana in 1948 described a new method known as cystectomy (capsule resection) ${ }^{12}$ All these techniques are conservative methods, suitable for uncomplicated cysts.

The choice of surgical technique depends on the conditions encountered during surgery. Conservative surgical techniques, especially cystotomy and capitonnage of the residual cavity, are the methods of choice in our clinic (table 1). Many authors emphasise that during the removal of the cyst after needle aspiration it is practically impossible to avoid spilling the contents into the thorax. ${ }^{135141521}$ Protection of the operative field with saline moistened gauzes, gentle manipulation of the cysts, and irrigation of the cavity with a scolicidal agent (such as sodium chloride $3 \%$ ) helps to prevent recurrence. In our series only eight patients had a recurrence, of whom seven had had a ruptured cyst before operation; only one was in the uncomplicated group. This low recurrence rate shows the

Table 4 Numbers of postoperative complications

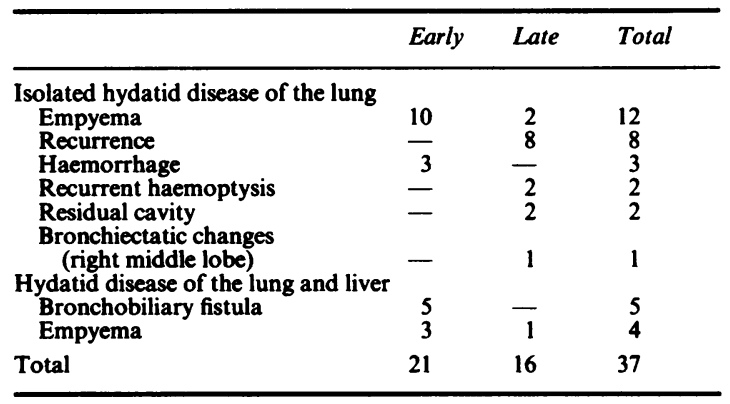

excellence of the cystotomy and capitonnage technique. Enucleation and obliteration of the residual cavity (the Ugon or Barrett method) is generally performed on peripherally located and small or moderate sized cysts. If the cyst is very tense or very large it is almost impossible to remove it without rupturing it. Haemorrhage and air leak during dissection of the pericystic space is the main disadvantage of Fontana's method. ${ }^{35}$ After resection of the capsule the remaining cavity may be difficult to obliterate.

Although some authors recommend leaving the cavity open ${ }^{11522}$ we prefer to obliterate it because of the risk of infection after haematoma formation. After cystotomy a potential cavity remains, which might permit abcess formation.

As a rule the lung parenchyma should be preserved as far as possible in patients with pulmonary disease and radical procedures avoided. If, however, bronchiectasis or severe inflammation is present the affected lung should be excised. When very large or multiple cysts have destroyed lung parenchyma, lobectomy or pneumonectomy should be performed. Lung resection for hydatid disease was first reported by Vaccarezza and Tricerri in $1951 .{ }^{23}$ Lung resection was carried out in 99 of our patients with complicated cysts. The complications included parenchymatous lung involvement simulating a lung abcess despite long term antibiotic treatment, multiple unilobar liver cysts with severe lung destruction, and lung destruction by infected liver cysts with intrathoracic extension. We also prefer more radical surgery when there is bronchiectasis complicating hydatid disease, severe haemorrhage, or fibrosis of the lung parenchyma. Resection should be avoided in children if possible because the damaged lung parenchyma has a great capacity for recovery. ${ }^{357}$ Most of the resection procedures in our series were performed before 1978; 


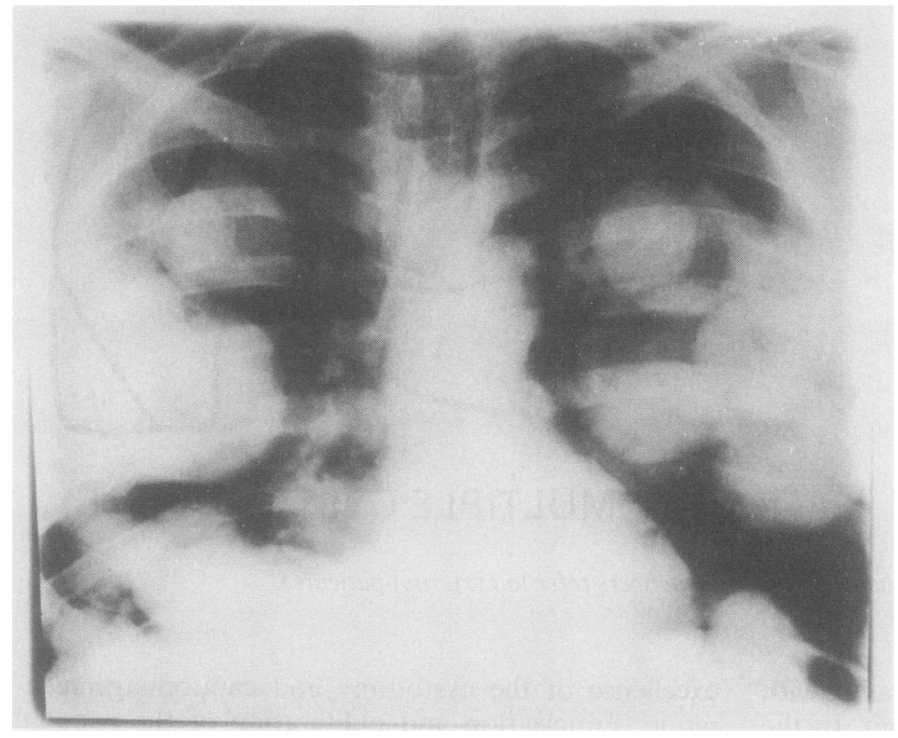

Fig 8 Bilateral multiple hydatid cysts.

since then they have been performed in only a few patients.

If there is a liver cyst or an extension of a liver cyst into the right hemithorax, we prefer to use the thoracic transpleural approach to manage the liver disease. When the hepatic cyst is uncomplicated it may be removed by using simple enucleation and the cavity closed. In the infected cyst with a biliary-bronchial fistula common duct drainage is indicated. ${ }^{3}$ We had to perform nasoduodenobiliary drainage in two cases.

When bilateral cysts are present some surgeons prefer a two stage thoracotomy, operating on the side with the larger cyst first, but others perform simultaneous bilateral thoracotomies. ${ }^{3514}$ We performed a two stage thoracotomy in 22 patients before 1978. From 1979 to 198760 patients with bilateral lung cysts had a median sternotomy but were not included in this series, having been reported elsewhere. ${ }^{24} \mathrm{We}$ prefer a one stage operation via a median sternotomy if there is no contraindication, such as the presence of an infected cyst with severe parenchymatous disease needing resection, an empyema following rupture of an infected cyst into the pleura, or a liver cyst with pleural extension. This method is more economical, causes less pain, and is better tolerated than two thoracotomies.

We conclude that surgery should be the primary treatment for most patients with pulmonary hydatid disease. Procedures that conserve lung tissue are appropriate for most patients, although there is a higher complication rate after these procedures than after excisional surgery. After the removal of the parasite the pericystic cavity should be obliterated to prevent secondary infection. Resection of lung tissue should be performed only when indicated. In patiente with coexisting hydatid cysts of the liver, especially those located within the right lobe and upper pole of the liver, the thoracic transpleural approach should b. used to manage both the liver and the lung cysts Finally, for bilateral cysts we prefer the media sternotomy approach in patients without empyema or massive infection who do not require extensive resect tion and in patients without liver cysts with intrathoracic extention.

\section{References}

1 Sarsam A. Surgery of pulmonary hydatid cysts. Review of 155 cases. J Thorac Cardiovasc Surg 1971;62: 663-8.

2 Hankin J, Dutz W, Kohnit E. Surgical treatment of ruptured and unruptured hydatid cysts of the lung. AnI Surg 1968;167:336-41.

3 Crausaz PH. Surgical treatment of hydatid cyst of the lung and hydatid disease of the liver with intrathoracie evolution. J Thorac Cardiovasc Surg 1967;53:116-29. N 4 Papadimitriou J. Surgical treatment of hydatid disease of

5 Xanthakis D, Efthimiadis M, Papadakis C, et al. Hydati $\$$ disease of the chest. Report of 91 patients surgicall treated. Thorax 1972;27:517-28.

6 Orueta A, Fau LF, Montero J, Prieto J, Duarte PG. Surgical treatment of hydatid cysts of the lung. $B r J D i s$ Chest 1974;68:183-6.

7 Aytac A, Yurdakul Y, Ikizler C, Olga R, Saylam A Pulmonary hydatid disease. Report of 100 patients? Ann Thorac Surg 1977;23:145-51. 
8 Yalav E, Ökten I. Surgical methods on pulmonary hydatid cysts [in Turkish]. Ankara: AƯTF Books, 1971:11-28.

9 Ulker M, Okur N. The state of unilocular disease of hydatid cysts in Turkey. J Turk Hydatid Ass 1967;9:5.

10 Ugon AV, Victoria A, Suarez H, Marcalin I. La lobectomia en el tratamiento de las secuelas del quiste hidatice de pulmon. Boln Soc Chirurg Uruguay 1946;17:465-70.

11 Barrett NR. Surgical treatment of hydatid cysts of the lung. Thorax 1947;2:21-57.

12 Perez-Fontana V. Nuevo metodo de uperar en el quiste hidatico del pulmon. Arch Pediatr Uruguay 1948;19: 5-36.

13 Hippocrates. Aphorisms VII:55.

14 Aletras H, Symbas PN. Hydatid disease of the lung. In: Shields TW, ed. General thoracic surgery. 2nd ed. Philadelphia: Lea and Febiger, 1983:645-57.

15 Ayusa LA, Peralta GT, Lazaro RB, Stein AJ, Sanchez JA, Aymerich DF. Surgical treatment of pulmonary hydatidosis. J Thorac Cardiovasc Surg 1981;82:569-75.

16 Braitwaite PA, Roberts MS, Allan RJ, Watson TR. Clinical pharmacokinetics of high dose mebendazole in patients treated for cystic hydatid disease. Eur J Clin Pharmacol 1982;22:161-96.

17 Frech CM. Mebendazole and surgery for human hydatid disease in Turkana. Afr Med $J$ 1984;61:113-9.
18 Saimot AG, Meulemans A, Grimieux AC, Giovangeli MD, Hay JM, Delaitre B, Coulard JP. Albendazole as a potential treatment for human hydatidosis. Lancet 1983;ii:652-6.

19 Morris DL, Clarkson MJ, Stallbaumer MF, Pritchard J, Jones RS, Chinnery JB. Albendazole treatment of pulmonary hydatid cysts in naturally infected sheep: a study with relevance to the treatment of hydatid cysts in men. Thorax 1985;40:453-8.

20 Allende JM, Langer L. Tratamiento de los quistes hidaticos de pulmon. Bol Y Trab Acad Argent de Cir 1947;31:536-40.

21 Wolcott MW, Harris SH, Briggs JN, Dobell ARC, Brown RK. Hydatid disease of the lung. $J$ Thorac Cardiovasc Surg 1971;62:456-69.

22 Saidi F. Surgery of the hydatid disease. Philadelphia: Saunders, 1976:156.

23 Vaccarezza OA, Tricerri FE. Resultados del tratamiento quirirgico del quiste hidatico del pulmon. A proposito de 41 casos tratados par reseccion de pulmon sin mortalidad. Prensa Med Argent 1951;38:1079-83.

24 Çetin G, Doğan R, Yüksel M, Alp M, Uçanok K, Kaya S, Ünlü M. Surgical treatment of bilateral hydatid disease of the lung via median sternotomy: experience in 60 consecutive patients. Thorac Cardiovasc Surgeon 1988;36:114-7. 